https://doi.org/10.36396/MS.2019.14.03.005

\title{
Коагуляционные свойства мембранных микрочастиц тромбоцитов, эритроцитов, лейкоцитов и эндотелиальных клеток
}

\author{
О.А. АНТОНОВА, Н.В. ГОАУБЕВА, О.А. ШУСТОВА, В.В. ЯКУШКИН, А.В. МАЗУРОВ
}

ФГБУ «Национальный медицинский исследовательский центр кардиологии» Министерства здравоохранения Российской Федерации, Москва, Россия

\begin{abstract}
Мембранные микрочастицы (МЧ) образуются при активации и/или поврежцении клеток. Они обладают коагуляционной активностью (ускоряют свертывание крови), так как содержат на своей поверхности фосфатидилсерин - субстрат Аля образования коагуляционных комплесов, а некоторые из них - тканевой фактор (ТФ), главный инициатор коагуляционных реакций. Ширкулируюшие в кровотоке МЧ продушируются клетками крови и эндотелиальными клетками сосудистой стенки, и их содержание может меняться при различных патологических состояниях. Сравнительные in vitro исследования показали, что наибольшей способностью ускорять свертывание плазмы крови обладают МЧ моноцитов и эндотелиальных клеток и более низкой - МЧ тромбоцитов, эритроцитов и гранулоцитов (нейтрофимов). Эти различия обусловлены главным образом присутствием в МЧ моноцитов и эндотелиальных клеток активного ТФ и отсутствием его в МЧ тромбоцитов, эритроцитов и гранулоцитов. Вариации размера МЧ различного клеточного происхождения сушественно не влияют на их коагуляционные свойства. Таким образом, на коагуляционный (протромботический) потенциал крови могут оказывать влияние в первую очередь МЧ, экспрессируюшие ТФ, источником которых могут быть активированные и/или поврежденные моноциты и эндотелиальные клетки.
\end{abstract}

Киючевые слова: мембранные микрочастицы, коагуляция крови, фосфатидилсерин, тканевой фактор, тромбоциты, эритроциты, мейкоциты, эндотелиальные киетки.

\section{Coagulation properties of membrane microparticles of platelets, erythrocytes, leukocytes and endothelial cells.}

ANTONOVA O.A., GOLUBEVA N.V., YAKUSHKIN V.V., SHUSTOVA O.A., MAZUROV A.V.

National Medical Research Center for Cardiology, Russian Ministry of Health, Moscow, Russian Federaion

\begin{abstract}
Membrane microparticles (MPs) are formed upon cell activation and/or damage. They possess coagulation activity (accelerate blood clotting) since they contain on their surface posphatidylserine, substrate for assembling coagulation complexes, and some of them tissue factor (TF), major initiator of coagulation reactions. Circulating MPs are produced by blood cells and vessel wall endothelial cells and their amount could be changed in different pathological conditions. Comparative in vitro studies have shown that MPs derived from monocytes and endothelial cells have the highest and MPs derived from platelets, erythrocytes and granulocytes (neutrophils) much lower ability to accelerate blood plasma clotting. These differences are mainly determined by the presence of active TF in monocyte and endothelial MPs and its absence in platelet, erythrocyte and granulocyte MPs. Size variations of MPs of different cellular origin do not significantly affect their coagulation properties. Thus, coagulation (prothrombotic) blood potential could be influenced first of all by TF expressing MPs the source of which are activated and/or damaged monocytes and endothelial cells.
\end{abstract}

Key words: membrane microparticles, blood coagulation, phosphatidylserine, tissue factor, platelets, erythrocytes, leukocytes, endothelial cells.

\footnotetext{
Сведения об авторах:

Антонова Ольга Алексанцровна - НМИЦ кардиологии Минздрава России, e-mail: loa_lu@mail.ru

Голубева Нина Вмалимировна - НМИЦ кардиологии Минздрава России, e-mail: ngolubeva0@gmail.com

Шустова Ольга Алексанцровна - НМИШ кардиологии Минздрава России, e-mail: vesta21@yandex.ru

Якушкин Влахимир Влахимирович - НМИЦ кардиологии Минздрава России, e-mail: abc2109yb@mail.ru

Мазуров Алексей Влахимирович - профессор, главный научный сотрудник, и.о. руководителя лаборатории клеточной адгезии НМИЦ карАиологии Минздрава России, (ORCID ID 0000-0003-4470-0124) +7 (916) 627-05-43 (моб.), +7 (495) 414-37-35 (paб.); e-mail: avmazurov@list.ru, (автор, ответственный за переписку)
} 
Мембранные микрочастицы (МЧ) представляют собой везикулярные фрагменты плазматической мембраны, которые высвобождаются в окружающую среду при активации и/или повреждении различных клеток. МЧ имеют размер ог 100 до 1000 нм и содержал на своей поверхности белки «родигелькой клеки. Микрочасицы отличают ог еще одного типа внеклеточных мембранных частиц - эКзосом. Экзосомы имеют меньший размер, от 40 до 100 нм, образуются внутри клетки и секретируются после слияния с плазматической мембраной, содержащей их внутриклеточные мультивезикулярные тельца. И МЧ, и экзосомы могут переносить биологически активные молекулы (белки, липиды, нуклеиновые кислоты) от продуцирующей их клетки к другим клеткам организма [1,2]. Однако МЧ обладают также выраженной коагуляционной активностью, т.e. способностью ускорять реакции свертывания крови [3-5]. Микрочастицы, в отличие от экзосом, содержат на своей поверхности большое количество фосфатидилсерина [6-8] - отрицательно заряженного фосфолипида, служащего субстратом для сборки коагуляционных комплексов. Некоторые виды МЧ содержат также тканевой фактор (ТФ) - трансмембранный белок, запускающий реакции оагуляционного каскада [6-8].

Источниками циркулирующих в кровотоке МЧ могут быть клетки крови и эндотелиальные клетки сосудистой стенки. МЧ различного клеточного происхождения определяют с помощью проточной цитометрии, используя флюоресцентно меченые антитела против ров поверхности «родительских» клеток [5]. Количество МЧ в крови может изменяться при различных патологических состояниях (что, очевидно, является отражением активации/ повреждения соответствующих клеток), в частности у больных с тромботическими осложнениями сердечно-сосудистых патологий или высоким риском их развития. У больных с острым коронарным синдромом было зарегистрировано повышение МЧ тромбоцитов [9-12], эритроцитов [13-15], моноцитов $[16,17]$ и эндотелиальных клеток [16-19]. Увеличение количества МЧ тромбоцитов наблюдали у больных с тяжелым атеросклерозом [20], МЧ моноцитов - у больных сахарным диабетом [21, 22], а МЧ эндотелиальных клеток у больных с тромбоэмболией [23]. Так как МЧ коагуляционно активны, они могут влиять и на протекание свертывающих реакций в процессе тромбообразования. В связи с этим актуальным вопросом является сравнительная характеристика коагуляционной активности МЧ различного клеточного происхождения

В серии работ, выполненных в последние годы, мы сравнивали коагуляционную активность и некоторые другие характеристики получаемых in vitro МЧ клеток тромбоцитов, эритроцитов, моноцитов, гранулоцитов (нейтрофилов) и эндотелиальных клеток [24-27]. В настояшем обзоре полученные нами результаты обобшены и сопоставлень с данными других авторов.

Для получения МЧ различного клеточного происхождения использовали тромбошиты, эритрошиты, моношиты и гранулошиты, вьделенные из крови злоровых доноров, культивируемые моношитарные ктетки линии ТНР-1 и кульиивируемие эндотелиальные клетки пупочнй вены

человека. Тромбоциты активировали ТRAP (Thrombin Receptor Activating Peptide - пептид, активирующий peRecop Acly THP-1, грину

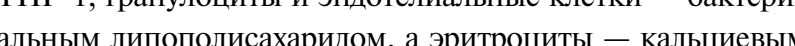
ионодор А23187. Образоваршиеся МЧ - вальиевыу тонно толси слер ийини қол рание при 20000 шенную эндогенных М Ч (центрифугиро-

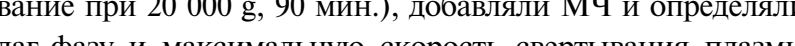
лаг-фазу и максимальную скорость свертывания плазми (образование фибрина) после внесения кальция. Для из учения участия фосфатидилсерина и ТФ в свертывающих реакция истолзовли блокаор фосфатидилсерина, бело

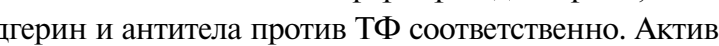

\section{Таблица 1. Параметры свертывания плазмы в присутстви}

\begin{tabular}{|c|c|c|}
\hline Источник МЧ & Ааг-фаза, мин. & Умакс, А450/мин \\
\hline $\begin{array}{l}\text { Моноциты } \\
(\mathrm{MO})(\mathrm{n}=10)\end{array}$ & $1,8 \pm 1,2$ & $37,0 \pm 15,0$ \\
\hline $\begin{array}{l}\text { Моношитарные } \\
\text { ксетки ITP-11 } \\
\text { (THP) (n=10) }\end{array}$ & $\begin{array}{c}4,6 \pm 1,4 \\
\mathrm{p}(\mathrm{MO})<0,001\end{array}$ & $\begin{array}{c}31,3 \pm 9,0 \\
\mathrm{p}(\mathrm{MO})=0,341\end{array}$ \\
\hline $\begin{array}{l}\text { Эннотемиальные } \\
\text { киетки } \\
\text { (ЭК) (n=6) }\end{array}$ & $\begin{array}{c}4,9 \pm 1,6 \\
\mathrm{p}(M O)<0,001 \\
\mathrm{p}(\mathrm{THP})=0,701\end{array}$ & $\begin{array}{c}26,8 \pm 7,5 \\
\mathrm{p}(\mathrm{MO})=0,147 \\
\mathrm{p}(\mathrm{THP})=0,324\end{array}$ \\
\hline $\begin{array}{l}\text { Тромбошиты (ТЦ) } \\
(\mathrm{n}=4)\end{array}$ & $\begin{array}{c}8,9 \pm 1,3 \\
\mathrm{p}(\mathrm{MOO})<0,001 \\
\mathrm{p}(\mathrm{THP})<0,001 \\
\mathrm{p}(\exists \mathrm{O})<0,001\end{array}$ & $\begin{array}{c}25,1 \pm 5,3 \\
\mathrm{p}(\mathrm{MO})=0,011 \\
\mathrm{p}(\mathrm{THP})=0,046 \\
\mathrm{p}(\mathrm{ЭK})=0,565\end{array}$ \\
\hline $\begin{array}{l}\text { Гранулоциты (ГР) } \\
(\mathrm{n}=6)\end{array}$ & $\begin{array}{c}8,9 \pm 3,1 \\
\mathrm{p}(\mathrm{MO})<0,001 \\
\mathrm{p}(\mathrm{THP})<0,001 \\
\mathrm{p}(\mathrm{YK})=0,019 \\
\mathrm{p}(\mathrm{TL})=0,961\end{array}$ & $\begin{array}{c}14,7 \pm 4,5 \\
p(M O)=0,004 \\
p(T H P)=0,001 \\
p(Э K)=0,007 \\
p(T \sqcup)<0,001\end{array}$ \\
\hline $\begin{array}{l}\text { Эритроииты (ЭР) } \\
(n=11)\end{array}$ & $\begin{array}{c}11,5 \pm 1,8 \\
p(M O)<0,001 \\
p(T H P)<0,001 \\
p(Э K)<0,001 \\
p(T \sqcup)<0,001 \\
p(\Gamma \sqcup)=0,040\end{array}$ & $\begin{array}{c}11,3 \pm 2,7 \\
p(M O)<0,001 \\
p(T H P)<0,001 \\
p(\exists K)<0,001 \\
p(T \sqcup)<0,001 \\
p(\Gamma \sqcup)=0,073\end{array}$ \\
\hline
\end{tabular}

Коагуляционную активность Мч различного происхождения изучали с помощью модифицированного теста рекальцификации плазм Свертывание плазмы (образование фибрина) определяли после добавления кальция, регистрируя оптическую плотность при 450 нм (А450. g, 90 мин.), добавляли МЧ в количестве $1,5 \times 10^{7}$ и измеряли лаг-фазу и максимальную скорость свертывания (Умакс). Приведены срелние стандартнне отклонения в скобках указано количество препаратов Мч (n). p (МО), p (ТНР), p (ЭК), p (ТЦ) и р (ГЦ) - достоверности отличий о групп «Моношить» «Моношитарные ктетки ТНР-1», «Эндотелиальн клеткиљ, «Тромбониты» и «Гранулошиты» соответственно (-қкритери Стьюдента). Лаг-фаза и Умакс для плазмы без МЧ составили 23,3+5, мин и 8,5+2,0 А450/мин. (n=23); достоверность отличий обоих показ

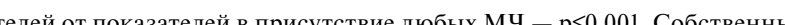
обобшенные данные [26, 27$]$
Таблича 2. Активный ТФ в МЧ разиичного кметочного происхожАения

\begin{tabular}{|c|c|}
\hline Источник МЧ & Активный ТФ, фмомь/108МЧ \\
\hline Моноциты (n=15) & $1,97 \pm 2,20$ \\
\hline $\begin{array}{l}\text { Моношитарные клетки } \\
\text { THР-1 (n=9) }\end{array}$ & $1,54 \pm 1,17$ \\
\hline Эндотемиамьные кметки (n=10) & $0,79 \pm 0,23^{*}$ \\
\hline Тромбоциты (n=4) & 0 \\
\hline Гранулошиты (n=6) & 0 \\
\hline Эритроииты (n=4) & 0 \\
\hline
\end{tabular}

Количество активного ТФ в МЧ различного происхождения определяли по его способности активировать фактор $\mathrm{X}$ с помощью хромогенного теста, добавляя в пробу 0,25х108 МЧ (моноциты, гранулоциты) $0,5 \times 10^{8}$ МЧ (моноцитарные клетки THP-1), 1,0х108 МЧ (эндотелиальные клетки и тромбоциты) и 5,0х10 $10^{8}$ Ч (эритроциты). В скобках количество препаратов МЧ (n). Представлены средние \pm стандартны отклонения количества активного ТФ в М 4.0 - ниже порога чувствительности метода ( $<0,02$ фмоль в пробе). * - p<0,0,5 - достоверност отличий от группы «Моноцитарные клетки ТНР-1) (t-критерий Стьюдента). Различия между группами «Моноциты» и «Моноцитарнь клетки ТНР-1» и группами «Моноциты» и «Эндотелиальные клетки

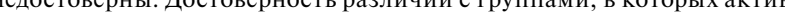
ность ТФ не регистрировалась, не определяли. Собственные обобщенные данные [24, 26, 27].

ность ТФ в МЧ оценивали с помощью хромогенного теста ро его способности активировань фактор X. Также в наших работах мы определяли размер МЧ различного клеточного

Все МЧ ускоряли свертыв вых свертывания представлены на рис. 1, а обобшаюшие данные - в табл. 1). При этом блокирование фосфатидилсерина лактадгерином полностью подавляло свертывание плазмы (см. рис. 1) [26, 27]. Наиболее высокую коагуляционную активность (короткие лаг-фазы и максимальные скорости свертывания) демонстрировали МЧ моноцитов, моноцитарных клеток ТНР-1 и эндотелиальных клеток. Существенно более низкая активность наблюдалась у М тромбошитов, гранулошитов и эритрошитов (см. табл. 1) $[26,27]$. Дальнейшие исследования показали, что МЧ моноцитов, клеток ТНР-1 и эндотелиальных клеток содержат активный ТФ. Антитела против ТФ удлиняли лаг-фазу свертывания в присутствии этих МЧ, и в них была зарегистрирована активность ТФ с помощью хромогенного теста. В то же время активный ТФ не был обнаружен в МЧ тромбоцитов, гранулоцитов и эритроцитов. Антитела против ТФ не влияли на свертывание в присутствие этих МЧ, и в них не удалось определить активность ТФ в хромогенном тесте. Примеры действия антител против ТФ на свертывание плазмы в тесте рекальиификании привесени рис. 1, а результаты определения активности ТФ во всех иипах МЧ - в табл. 2 [24, 26, 27]. МЧ моношитов и клеток ТНР-1 содержали несколько больше активного ТФ, чем МЧ эндотелиальных клеток, однако встедси шого разброса данных различия достигали достоверного . с ТФ в МЧ моношитов, клеток ТНР-1 и эн -огелиаси леток приводит к виравииванио показателей свертыра кия привдит к выравниванию показаялей свертывавия в присусьий эих МЧ и МЧ тромбоцитов и гранулоциов. Таким образом, совокупность полученных данных указывает на то, что более высокая коагуляционная акмокосьь М моноцитов (в том числе моноцитарных кле-

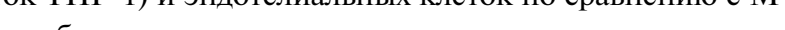
ромбоцитов, гранулоцитов и эритроцитов определяетс вым образом наличием в них активного ТФ.

В наших работах мы впервые провели сравнительные исследовани размера МЧ различного клеточного происхождения [25-27], предполагая, что размер МЧ может потенциально влиять и на их коагуляционную активность. Для определения размера МЧ использовали метод динамического светорассеивания. В зависимости от типа клеток-продуцентов размер (средний диаметр) МЧ варьировался в диапазоне от 200 до 600 нм. Данные табл. 3 демонстрируют, что наиболее крупными были МЧ эндотелиальных клеток и гранулоцитов (средний диаметр около 600 нм), несколько более мелкими - МЧ моноцитов, клеток ТНР-1 и тромбоцитов (средние диаметры приблизительно от 400 до 500 нм) и существенно более мелкими оказались МЧ эритроцито

\section{Таблица 3. Размер МЧ различного кметочного}

\begin{tabular}{|c|c|}
\hline Источник МЧ & Среаний миаметр МЧ, нм \\
\hline $\begin{array}{l}\text { Энцотемиальные киетки (ЭК) } \\
(\mathrm{n}=6)\end{array}$ & $591 \pm 21$ \\
\hline $\begin{array}{l}\text { Гранулоииты (ГР) } \\
(\mathrm{n}=4)\end{array}$ & $\begin{array}{c}581 \pm 10 \\
p(Э K)=0,376\end{array}$ \\
\hline $\begin{array}{l}\text { Моноииты (MO) } \\
(\mathrm{n}=10)\end{array}$ & $\begin{array}{c}485 \pm 61 \\
\text { p (ЭК)=0,002 } \\
\text { p(ГЦ) }=0,016\end{array}$ \\
\hline $\begin{array}{l}\text { Моношитарные кметки ТНP } 1 \\
(\text { THP) } \\
(\mathrm{n}=7)\end{array}$ & $\begin{array}{c}410 \pm 35 \\
p(Э K)<0,001 \\
p(\Gamma \bigsqcup)<0,001 \\
p(M O)=0,017\end{array}$ \\
\hline $\begin{array}{l}\text { Тромбошиты (ТЦ) } \\
(\mathrm{n}=10)\end{array}$ & $\begin{array}{c}382 \pm 56 \\
\mathrm{p}(Э K)<0,001 \\
\mathrm{p}(\Gamma \bigsqcup)<0,001 \\
\mathrm{p}(\mathrm{MO})=0,004 \\
\mathrm{p}(\mathrm{THP})=0,276\end{array}$ \\
\hline $\begin{array}{l}\text { Эритрошиты (ЭР) } \\
(\mathrm{n}=9)\end{array}$ & $\begin{array}{c}213 \pm 14 \\
p(Э K)<0,001 \\
p(\Gamma \sqcup)<0,001 \\
p(M O)<0,001 \\
p(T H P)<0,001 \\
p(\text { (Tப) }<0,001\end{array}$ \\
\hline
\end{tabular}

Размер (средний диаметр) МЧ различного происхождения определял методом динамического светорассеивания. Прелставлени средине стандартные отклонения, в скобках указано количество препаратов $\mathrm{M \Psi}(\mathrm{n})$, $\mathrm{p}($ ЭК), p (ГР), p (МО), p (ТНР), p (ТЦ) - достоверности отличи от групп «Эндотелиальные клетки», «Гранулоциты», «Моноцитарные 作, «оношиты» и «Тромбоциты» соответственно (t-критерий Стьюдента). Собственные обобщенные данные [25-27]. 
(средний диаметр около 200 нм). Эти данные показали отсут-

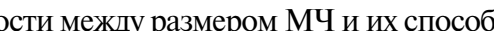
ностью стимулировать свертывающие реакции. Например когуляшионн наиболее активные МЧ моношитов и клеток THР-1 были не самими крупными, а малоактивные МЧ гранулоцитов, наоборот, были одними из самых крупных Возможно, лишь очень низкая активность МЧ эритроцитов, которая была даже несколько ниже, чем у МЧ тромбоцитов и гранулоцитов (см. табл. 1), также не экспрессирующих ТФ, частично определяется их очень мелким размером.

Сравнительные исслелования МЧ моношитов и тромбоцитов проводились в работах М. Aleman и соавт. [28] и С. Tripisciano и соавт. [7], а МЧ моноцитов, тромбоцито и эритроцитов - в работе P. Van Der Mejiden и соавт. [29]. Эти авторы использовали для оценки коагуляционной активности МЧ тест генерации тромбина. В их работах, как и в наших исследованиях, было продемонстрировано наличие ТФ в МЧ моноцитов и его отсутствие в МЧ тромбоцитов и эритроцитов и показано, что благодаря этому МЧ моноцитов стимулируют образование тромбина сильнее, чем МЧ тромбоцитов и эритроцитов. Отсутствие ТФ в МЧ эритроцитов было отмечено также в еще одной публикации [30]. Экспрессия ТФ в МЧ эндотелиальных клеток наряду с нашими исследованиями была зарегистрирована и рядом других авторов [31-34].

Проведенные нами исследования и данные литературы показали, что коагуляционно наиболее активными являются МЧ, экспрессирующие ТФ. Такие МЧ продуцируются моноцитами и эндогелиальыми клетками, и именно эти МЧ могут оказывать наибольшее влияние на реакции свертывания крови в процессе тромбообразования. 00347

РФФИ №17-04-

\section{Авторы заявляют об отсутствии конфликта интересов.}

ЛИTEPATYPA/REFERENCES

Raposo G, Stoorvogel W. Extracellular vesicles: exosomes, microvesicles, and
friends. Journal of Cell Biology. 2013;200:373-383. https://doiorg/10.1083/ friends. Journal of
jcb.201211138

jeb.201211138 new players in metabolic and cardiovascular discease. Journal of Endocrinology. 2016;228:R57-71. https://doi.org//0.1530/JOE-15-0201

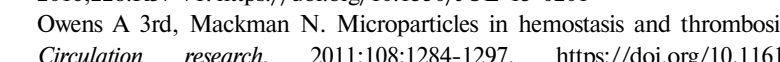

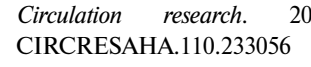

Lacroix R, Dubois C, Leroyer A, Sabatier F. Dignat-George F. Revisited role of microparticles in arterial and venous thrombosis. Journal of Thrombosisis and

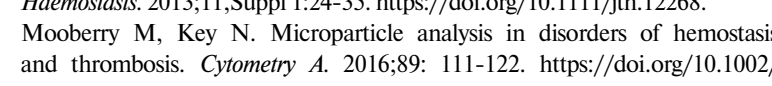

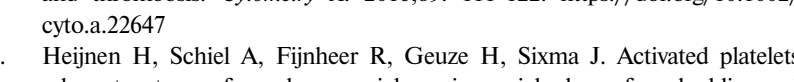
release two types of membrane vesicles: microvesicles by surface shedding and
exosomens derived from exocytosis of multivesicular bodies and a-granules Blood. 1999;94:3791-3799.

Tripisciano C, Weiss R, Eichhorn T, Spittler A, Heuser T, Fischer M.B, Weber Contributions of Phosphatididyserine, Tissue Factor and Cellulurar Origin. Scientifif Reports: 2017; 7(1),6522. https://doi.org/10.1038/44 1598-017-03262-2
Рисунок 1. Ускорение свертывания пмазмы МЧ эритрошитов

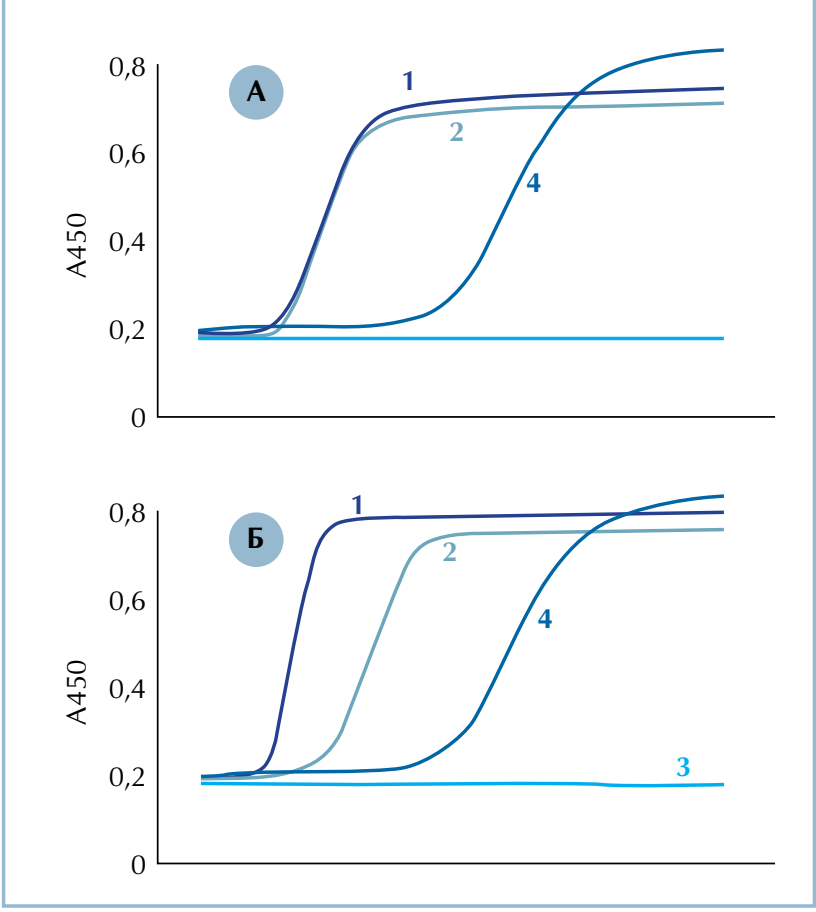

Тест рекальцификации. Эффекты анти-ТФ антител и лактадгерин. К плазме здорового донора, лишенной эндогенных МЧ (центрифугирование $20000 \mathrm{~g}, 90$ мин), добавляли $3 \times 10^{7}$ МЧ эритроцитов (А) ил 0,375x107 Мч моноцитарных клеток THР-1 (Б). Свертывание плазм регистрировали после добавления $\mathrm{CaCl} 2$ по изменению оптическо плотности при 450 нм (А450). Кривые 1 - только МЧ, кривые 2 - МЧ 10 мкг/мл анти-ТФ антител, кривые 3 - МЧ + 150 нм лактадгерина, кривые 4- плазма без Мч. Представлены воспроизводимые кривые из не

Skotland T, Hessvik N, Sandvig K, LlorenteA. Exosomall lipid composition
and the role of ether lipids and phosphoinositides in exosome biolog and the role of ether lipids and phosphoinositides in exosome biology
Journal of Lipid Research. 2018. pii: jlr. R084343. https://doi.org/10.1194/ jlr.R084343 (Epub ahead of print) Van der Zee P, Biro E, Ko Y, de Winter R, Hack C, Sturk A, Nieuwland
R. P-selectin- and CD63-exposins platelet microparticles reflect platele R. P-selectin- and CD63-exposing platelet microparticles reflect platele
activation in peripheral arterial disease and myocadrial infarction. clinchem.2005.057414 microparticles during and after acute coronary syndrome. Journal
of Thrombosis and Haemostasis. 2012;107:1122-1129. https://doi. of Thrombosis and Haemostasis. 2012;107:1122-1129. https://dol
org/10.1160/TH11-11-0779 Kafian S, Mobarrez F, Wall $\mathrm{n} \mathrm{H}$, Samad B. Association between platelet reactivity and circulating platelet-derived microvesicles in patients with
acute coronary syndrome. Platelets. 2015;26:467-473. https://doi.org/10.

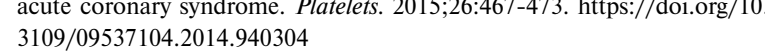
12. Namba M, Tanaka A, Shimada K, Ozeki Y, Uehata S, Sakamoto
T, Nishida Y, Nomura S, Yoshikawa J. Circulating platelet-derived T, Nishida Y, Nomura S, Yoshikawa J. Circulating platelet-derived
microparticles are associated with atherothrombotic events: microparticles are associated with atherothrombotic events.
marker for vulnerable blood. Arteriosclerosis, Thrombosis and
Vascular. Biology, 2007:27:255-256. https://doi.org /10.1161/01. Vascular Biology. 2007; 272
ATV.0000252064.97632.2c
13. Giannopoulos G, Oudatzis G, Paterakis G, Synetos A, Tampaki E, Bouras G Hahalis G, Alexopoulos D, Tousoulis D, Cleman M, Stefanadis C, Deffereos

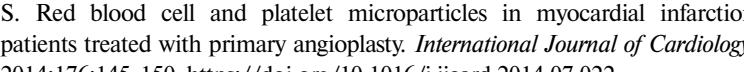

14. Suades R, Padr T, Vilahur G, Martin-Yuste V, Sabat M, Sans-Rosell J
Sionis A, Badimon L Growing thrombi release increased levels of CD235at microparticles and decreased levels of activated platelet derived microparticles.

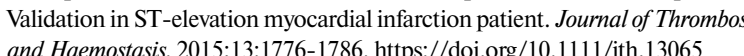

15. Giannopoulos G, Vrachatis D, Oudatzis G, Paterakis G, Angelidis C, Koutiva A, Sianos G, Cleman M, Filippatos G, Lekakis J, Deffereos S. Circulating erythrocyte microparticles and the biochemical extent of myocardial injury
ST elevation myocardial Infarction. Cardiology. 2017: $136: 15-20$. https///doi. org/10.1159/000447625

16. Montoro-Garc a S, Shantsila E, Tapp L, L pez-Cuenca A, Romero A Hern ndez-Romero D, Orenes-Piero E, Manzano-Fern ndez S, Vald coronary syndromes relevance to fibrityiting microparticles in acule outcomes. Atheressclersosis. 2013;227:313-3222. hitps://doi.org/10.1016/_ atherosclerosis.2013.01.028

Crespo J, Ramaiola I, Martin-Yuste V, Sabat M, Sansand peripheral blood of $\mathrm{ST} \mathrm{L}$. Circulating microparticle signature in coronar

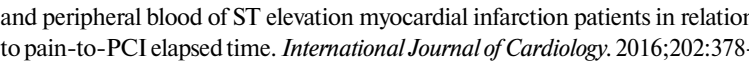
387. https://doio.org/10.1016/i.jicard.2015.09.011

18. Bernal-Mizrachi L, Jy W, Jimenez J, Pastor J, Mauro L, Horstman L, de in patients with acute coronary syndromes. American Heart Journa

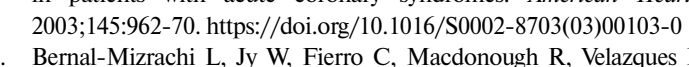

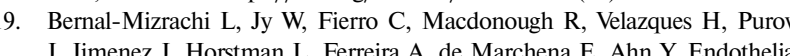
microparticles correlate with high-risk angiographic lesions in acute coronary
syndromes. International Journal of Cardiology. 2004;97:439-46. https://doi.

20. Tan K, Tayebjee M, Lynd C, Blann A, Lip G. Platelet microparticles and soluble P selectin in peripheral artery disease: relationship to extent of diseas and platelet activation markers. Annals of Medicizie. 2005;37:61-6. of monocyte-derived microparticles in patients with diabetic retinopathy.
Diabetes Research and Clinical Practice. 2006; $73: 241-248$. https://doDiaberes Ressarch and Clinical
org/10.1016/.j.diabres.2006.01.014

22. Omoto S, Nomura S, Shouzu A, Nishikawa M, Fukuhara S, Iwasaka Detection of monocyte-derived microparticles in patients with Type
diabetes mellitus. Diabetologia. 2002; $455550-555$. https://doi.org/10.1007/ s00125-001-0772-

23. Chirinos J, Heresi G, Velasquez H, Jy W, Jimenez J, Ahn E, Horstman L, platelelts, and leukocyte activation in patients with venous thromboembolism.
Journal of the American College of Cartiology. $2005 ; 45: 1467-1471$. https://doi org/10.1016/j:jacc.2004.12.075

12.075 . Шустов О Н. Якушиин В В. Голубее Н.В., Титаева Е.В., Добровольский А.Б, Мазуров АВ В Активность тва неввго фактора в микрочастицах продуцируемьхх і і vitro эндотелиальными клетками, моноцитами, гранулоцитами и тромбоцитами. Биохимия
2016:81 (2):206-214 [Khaspekova SG, Antonova OA, Shustova ON, Yakushkin
VV Golubeva NV Titeva EV Dobrovolcky AB, and Mazurov AV Acivity of tissue factor granulocytes, and platelets. Biochemistry (Moscow). 2016;81 (№ 2): 114-121.(In Russ.).] https:///doi.org/10.1134/5000629791602005X

стова О.Н., Антонова О.А., Карганов М.Ю., Мазуров А.В. Сравнение размера мембрандинамического свегорассеивания. Доклады Акалемии наук. Биохиии биофизика, молекудярная биология. 2016;470(2):223-226. [Alchinova IB,
Khaspekova SG, Golubeva NV, Shustova ON, Antonova OA, Kargano MYu, Mazurov AV. Comparison of the size of membrane microparticles of different cellular origin by dynamic light scattering. Doklady Bichemistry
and Biophysics. 2016;470:322-325.(In Russ.).]. https://doi.org/10.1134/

26. Shustova O, Antonova O, Golubeva N, Khaspekevova, Yakushhinin V, Aksuk
S, Alchinova I Karganov M, Mazurov A. Differential procoagulant activity of ( cells: impact of active tissue factor. Blood Coogulation and Fibrinolysis Антонова О.А., Шустова О.Н., Голубева Н.В., Якушкин В.В., Алчино И.Б., Карганов М.Ю., Мазуров А.В. Коагуляционнные свойства мем214-221. hppts://doi: 10.18097/PBMC20196503214 [Antonova ON Shustova ON, Golubeva NV, Yakushkin WV, Alchinova IB, Karganov M Y,, Mazuro AV. Coagulation properties of erythrocyte derived membrane microparticles.
Biomedical Chemistry (Moscow), Supplement Series B: Biomedical Chemistry monocyte- and platelet-derived microparticles towards thrombin generatio and fibrin formation and stability. Jurral of Thrombosis and Haemostasis

Van Der Meijden P, Van Schilfgaarde M, Van Oerle R, Renn T, ten Cate $\mathrm{H}$, Spronk $\mathrm{H}$. Platelet- and erythrocyte-derived microparticles trigger
thrombin generation via factor XIIa. Journal of Thrombosis and Haemostasis 2012;10:1355-1362. https:///di..org/10.1111/j.1538-7836.2012.04758.x.

Angelillo-Scherrer A. Red blood cell-derived microparticles isolated from blood units initiate and propagate thrombin generation. Transfusie Kagaw H Komiyama Y Nakamura S. Mivake T,

Masuda M, Takahashi H, Nomura S, Fukuhara S. Expression of function tissue factor on small vesicles of lipopolyssaccharide-stimulated human vasculler

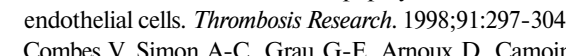

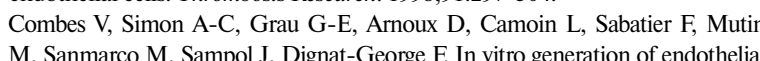
microparticles and possible prothrombotic activity in patients with lupus anticoagulant. Journal of

Detached endothelial cells and m, Selig M, Ingelfinger J, Grabowski $\mathrm{E}$ activity. Thrombosis Research. 2005;116:409-419. https://doi.org/10.1016/ Abid Hussein M, B i

Phospholipid composition of in vitro endotothelial microparticles and the in vivo thrombogenicit propertities. Thrombosis Research. 2008; $121: 1865-87$. 